\title{
Daily birth numbers in Passo Fundo, South Brazil, 1997-1999: trends and periodicities
}

M. Mikulecky ${ }^{1}$ and H.R.K. Lisboa ${ }^{2}$

\author{
${ }^{1}$ Institute of Preventive and Clinical Medicine, Bratislava, Slovakia \\ ${ }^{2}$ Departamento de Medicina Interna, Faculdade de Medicina, \\ Universidade de Passo Fundo, Passo Fundo, RS, Brasil
}

\section{Correspondence \\ M. Mikulecky \\ UPKM \\ Limbova 14 \\ SK 83301 Bratislava \\ Slovakia \\ Fax: + 421-02-5477-3906 \\ E-mail: mikuleky@upkm.sk \\ Research supported by the Ministry of Health of the Slovak Republic and the Institute of Preventive and Clinical Medicine, \\ Bratislava, Slovak Republic.}

Received November 14, 2001

Accepted June 3, 2002

\section{Abstract}

Between October 6, 1997 and April 30, 1999, 5011 births (mean: 8.76 per day) were registered in the city of Passo Fundo, South Brazil. The sequence of 572 daily birth numbers was not random (iteration test). Neyman distribution $(\mathrm{m}=\infty)$ showed the best fit. Clusters of days with higher birth numbers alternated with days with low numbers of births. Periodogram analysis revealed a significant periodicity of 6.98 days. The cosinor regression, testing 10 a priori supposed period lengths, found significant seasonality peaking in August-September and significantly highest birth numbers on Thursdays. Among the lunar and solar rotation cycles, the tropic lunar cycle and its 4th harmonic were most pronounced, in agreement with results concerning natality in Germany obtained by Svante Arrhenius in the 19th century. These findings confirm Derer-Halberg's concept of multiseptans. In addition to cycling, a significantly increasing linear trend with a daily increase of 0.0045 births was encountered. This documents a growth of the population in agreement with national statistical data.

\section{Introduction}

Cosmogeophysical changes undoubtedly influence many events occurring on earth. The seasons are the most straightforward example that the position of earth in relation to the sun induces changes in temperature and other parameters on our planet. The same is true for sea tides occurring according to the movement and position of the sun and the moon. Besides gravitational forces, there is a daily regular magnetic field variation arising from current systems caused by regular solar radiation changes and affecting the magnetosphere and the ionosphere. Changes in geomagnetic activity may act on living subjects (1).

The influence of cosmogeophysical factors on living organisms has long been studied, sometimes with contradicting results. For example, pronounced and persistent seasonal patterns in fertility have been observed in virtually all human populations. This seasonality increased in the 20th century in some high income, low fertility populations such as that of Sweden (2). Temperature did not play any role in explaining the pronounced June-July peak in conceptions in this country. Strong evidence, however, has been found that summer heat plays an important role in explaining the July-August trough in conceptions in the southern United States. For 
some populations, obviously factors other than temperature play an important role in birth seasonality.

There are conflicting reports about randomness of daily sequence of birth numbers in various geographic areas. A fluctuation along synodic lunar phases was and continues to be searched for with considerably contradictory results. The objective of this study was to address the question of random sequence. In the case of non-randomness, manifested as a clustering in time in the form of "miniepidemics", the possible presence of periodicities and parallelisms with some known cosmogeophysical cycles, including the synodic lunar one, will be tested besides the general trend, using appropriate chronobiometric tools.

\section{Subjects and Methods}

The daily numbers of spontaneous births in the city of Passo Fundo, RS, Brazil, from October 6, 1997 to April 30, 1999 were registered $^{1}$. The data were obtained on 572 consecutive days for three hospitals that have maternity units in the city, where $99 \%$ of deliveries take place. The number of births was taken from the register book of these hospitals after confirmation by the nurse in charge. Births eligible for study were those occurring by the vaginal route and by cesarean section due to obstetric indication (cephalic-pelvic disproportion, hypertensive disease of pregnancy) or due to fetal distress, and those in which the mother asked for surgical delivery but was already considered to be in the beginning of the normal labor (having more than three contractions in 10 $\mathrm{min})$. All these cases were included to insure the spontaneous character of deliveries. Elective cesarean births, considered to occur during working hours (7:30 am to $6: 00 \mathrm{pm})$, were not included in the study.

\footnotetext{
${ }^{1}$ The data file is available from either author's e-mail.
}

As descriptive statistics, the mean and $95 \%$ confidence interval were calculated for the given daily numbers (counts) of births using a formula based on a normal approximation of the Poisson distribution (3).

To test the randomness of the sequence of daily numbers of births the iteration test was used (4). The null hypothesis was tested against the one-sided alternative supposing a clustering effect. Moreover, the data were analyzed on the basis of null hypotheses supposing normal, Poisson, negative binomial and Neyman distributions type A, B and those with parameters $\mathrm{m}=8$ and $\mathrm{m}=\infty$ (5).

Periodogram analysis $(6,7)$ was subsequently used to test the presence of any significant periodicity.

The significance of a priori supposed periods (year, half year, synodic, anomalistic and tropical lunar cycles with their 4th harmonics, Bartels solar rotation cycle and social week with a precise 7.00-day period length) was tested by Halberg's cosinor regression $(8,9)$. Also a general linear trend was investigated. The data for cosinor analysis were transformed to moving averages from three successive observations each. The level of statistical significance was set at $\alpha=$ 0.05 . For the cosinor calculations, testing the presence of 10 period lengths together, the Bonferroni modification (10) of the $\mathrm{P}$ value was used to cope with the problem of spurious significance.

\section{Results}

The daily number of births ranged from 0 to 20 , with a mean of 8.76 births per day (95\% confidence interval 8.52-9.01) and a median of 8.5 births per day.

The one-sided iteration test rejected the randomness of sequence of daily birth numbers in favor of the clustering alterna- 
tive $(\mathrm{P}=0.047)$. In other words, there are days with significant accumulation of births - something like mini-assemblages - and those with lower numbers of deliveries. This was confirmed and made more precise by distribution testing (Table 1). The best fitting distribution appears to be - due to the highest $P$ value $(0.306>0.05)$ - the Neyman type $\mathrm{m}=\infty$ (Figure 1).

The result of the periodogram analysis was unequivocal (Figure 2, top). One range of significant period lengths was found, i.e., 6.95-6.98 days with $P$ values of 0.039-0.029.

Cosinor analysis disclosed (Figure 2) a significant linear increasing trend with a regression coefficient estimate of 0.0045 cases per day $(95 \%$ confidence interval 0.0035 $0.0054, \mathrm{P}<0.001)$. Table 2 gives the amplitudes as the point and $95 \%$ confidence estimates of percentage from the mesor (the starting zero position of the oscillation) and their significance. The time of the first peak for each of the ten tested period lengths is also given. There have been $30 \%$ of the variance explained by the cosinor regression. This estimate of the coefficient of determination $(0.30)$ corresponds to the estimate for the coefficient of nonlinear "correlation" (as the square root of 0.30 ) equal to 0.55 . Consequently, the significance of the latter for $\mathrm{N}=572$, i.e., for 572-12 (12= number of estimated parameters $)=560 \mathrm{de}$ grees of freedom, $\mathrm{P}<0.001$, speaks in favor of an excellent approximation of the data by the total approximating function.

\section{Discussion}

The novelty of this study is four-fold. First, the randomness of the sequence of daily numbers of deliveries was tested as the first step of the investigation using the iteration test as well as the Poisson and Neyman distributions. Only rejection of this null hypothesis justified the second step - a search for periodicities and subsequent hypothesizing concerning putatively linked cosmogeo- physical variables.

Second, not only a parallelism with synodic "lunar phases", commonly investigated and discussed, but also a parallelism with other cosmogeophysical cycles was taken into account.

Third, appropriate statistical techniques were used. Instead of the usually constructed plexogram in which all data are condensed into one ideal cycle, e.g., from the new moon over the full moon to the next new moon, etc., the chronogram was analyzed. The latter represents the original sequence of data, in our case from October 6, 1997 to April 30, 1999. This makes it possible to test the presence of several cycles together, taking into

Table 1. Results of testing different types of distributions.

\begin{tabular}{lcccccccc}
\hline & Normal & Poisson & Negative binomial & \multicolumn{5}{c}{ Neyman } \\
\cline { 5 - 9 } & & & & & A & B & $m=8$ & $m=\infty$ \\
\hline d.f. & 14 & 12 & 13 & 13 & 13 & 16 & 14 \\
Chi-square & 19.6 & 42.1 & 16.5 & 15.8 & 15.9 & 32.5 & 16.2 \\
$P$ value & 0.144 & 0.000 & 0.225 & 0.261 & 0.257 & 0.009 & 0.306 \\
\hline
\end{tabular}

d.f. $=$ degrees of freedom.

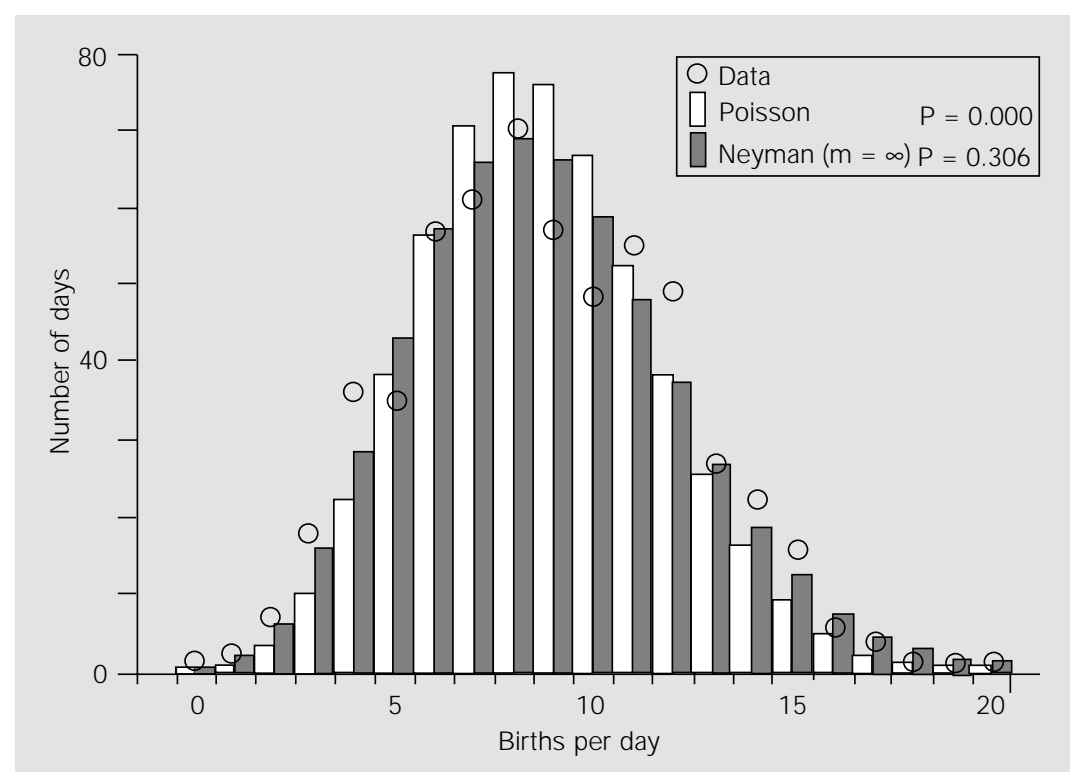

Figure 1. Number of days versus number of births per day. The distributions are indicated in the inset. 


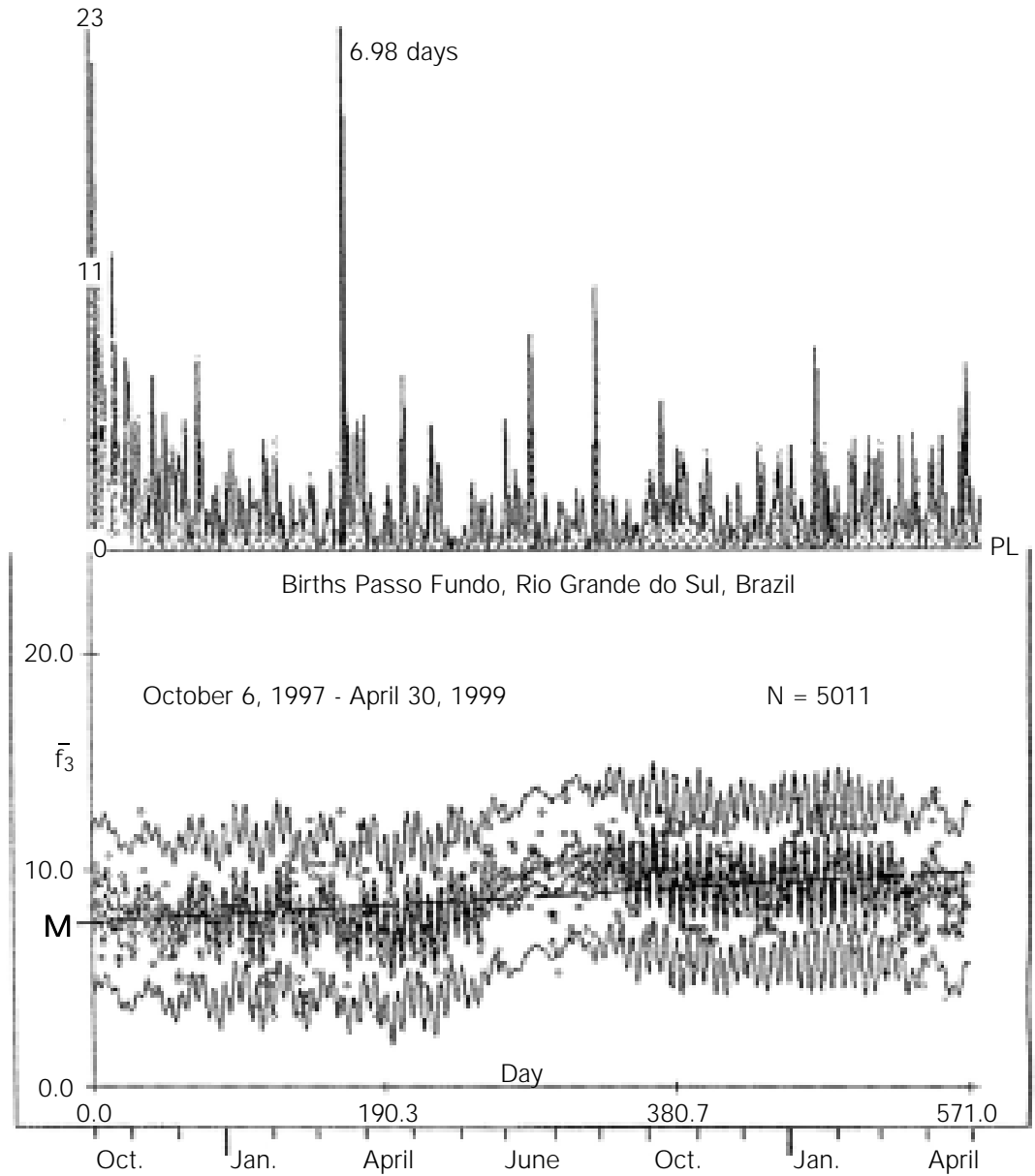

Figure 2. Top, Periodogram with the relative measure of significance (ordinate) versus period length (PL). Bottom, The chronogram of the daily birth numbers. Data are presented as open dots; the approximating regression function is accompanied by the limits of $95 \%$ confidence interval (for means, narrow) and tolerance (for separate data, wide). The very narrow confidence corridor results together with the central point estimate of the function into one heavy line. $M=$ mesor as the starting value of the linear trend function. account in our case three kinds of moon cycles, solar rotation cycle, social week and year seasons. This agrees with the reality of coexistence of many cycles in biomedical time data.

Fourth, as the outcome of these approaches, some interesting results were obtained, particularly the seasonality of births at a given location in the south hemisphere peaking in August and September, the weekly rhythm with the peak on Thursday and perhaps period lengths parallel to some lunar and solar cycles.

Our findings about the synodic lunar cycle should be compared with relatively numerous, often controversial reports in the literature. Guillon et al. $(11,12)$, analyzing millions of births in France, found peaks in May (northern hemisphere!), on Tuesday and a few days before the new moon. Agreement with our findings was only partial. On the other hand, Ghiandoni et al. (13-15) in Italy, with 1248 births, claimed that the maximum number of births was around the full moon in agreement with our finding. A similar experience was interpreted as a phenomenon connected to the fluctuation of barometric pressure (16). This concept, however, was not confirmed (17).

The most pronounced "cosmic" parallelism in our data appears to be that connected

Table 2. Chronobiometric parameters of Passo Fundo, Brazil birth data.

\begin{tabular}{lccccl}
\hline Period name & Mean period length (days) & \multicolumn{2}{l}{ Amplitude $(\%$ of mesor) } & Time of peaking \\
\hline Year & 365.25 & 8 & 11 & $14^{* * *}$ & September 16 \\
Half year & 182.63 & 3 & 6 & $9^{* * *}$ & February 8, August 8 \\
Synodic LC & 29.53 & 0.2 & 3 & $6^{*}$ & 14th day after the new moon \\
Synodic LC/4 & 7.38 & 1 & 4 & $7^{* *}$ & 3rd, 10th, 18th, 25th day after the new moon \\
Anomalistic LC & 27.55 & 20 & 48 & $76^{* *}$ & 6th day after perigee \\
Anomalistic LC/4 & 6.89 & -1 & 2 & 5 & 1st, 8th, 15th, 22nd day after perigee \\
Tropical LC & 27.32 & 25 & 69 & $114^{* *}$ & 15th day after maximal positive declination \\
Tropical LC/4 & 6.83 & 2 & 5 & $8^{* *}$ & 5th, 12th, 19th, 25th day after maximal positive declination \\
Bartels' solar RC & 27.00 & 10 & 31 & $51^{* *}$ & 20th day of the Bartels' cycle \\
Social week & 7.00 & 7 & 10 & $13^{* * *}$ & Thursday
\end{tabular}

LC = lunar cycle, RC = rotation cycle. For amplitude as $\%$ of mesor, the lower $95 \%$ confidence limit, the point estimate and the upper $95 \%$ confidence limit, respectively, are given.

$* \mathrm{P}<0.05, * * \mathrm{P}<0.01$, and ${ }^{* * *} \mathrm{P}<0.0001$ are the significance for the amplitude compared to zero using the Student $\mathrm{t}$-test. 
to the tropical lunar cycle and its 4th harmonic. This confirms the results of Arrhenius (18) published one century ago and commented by one of us (19). Even the phase of the tropical lunar cycle with peaking numbers of births seems to agree roughly.

Equally numerous investigators, however, were unable to find any lunar "dependence" of daily birth frequencies (20-24). A detailed historical survey of negative results with a critical approach to positive ones was provided by Wunder $(25,26)$.

The controversial debate concerning the "moon and births" issue appears to be extant in the nineties ( 8 papers in our review), the same way as in the eighties (6 papers in our review). Since 1998, only two papers $(27,28)$ appeared in Science Citation Index/Current Contents (SCI/CC) journals. Both, however, were dealing with the topic which touches astrology - a feature which is not present in our paper. Nevertheless, they appeared in journals covered by the SCI/CC system!

In the literature, the issue of a time parallelism between some medical events and the synodic lunar cycle is discussed also for some topics of human pathology, usually with negative conclusions. Nevertheless, a cycling parallel to phases of synodic moon was described by our group for paroxysmal tachyarrhythmia (29) and for acute infectious gastroenteritis (30). The second and 4th harmonic of the synodic lunar cycle approximately fortnight and week periods were unequivocally present in these data.

A significant 6.5-day rhythm was described originally by Derer (31) for leuko- cyte counts after treatment of leukemia. On this basis, a general biological concept of circaseptans - approximately 7-day rhythms and their harmonics (the circasemiseptan, around 3.5 days) as well as their multiples (e.g., circadiseptan, i.e., fortnight) - was created $(32,33)$.

To conclude, the sequence of daily birth numbers in this study was not random: clusters of days with higher birth numbers alternating with those having low numbers of births were detected. Periodogram analysis revealed a significant periodicity of 6.98 days. A significant seasonality peaking in August-September and significantly higher birth numbers on Thursdays were found. Among the lunar and solar cycles, the tropic lunar cycle and its 4th harmonic were the most prominent ones. Besides the cycling, a significantly increasing linear trend with a daily increase of 0.0045 births was encountered and attributed to the growth of the population in Brazil.

Results presented in this paper should stimulate similar studies in Brazil as well as worldwide, including either hemisphere. Possible differences and agreements could expand the body of knowledge in the field of chronobiology of human reproduction.

\section{Acknowledgments}

We would like to thank Drs. Benhur Madalosso and Sheila Meincke Eikhoss, Medical School of the University of Passo Fundo, for their valuable effort in collecting the data from the hospitals.

\section{References}

1. Weaver J C, Vaughan TE \& Astumian RD (2000). Biological sensing of small field differences by magnetically sensitive chemical reactions. Nature, 405: 707-709.

2. Lam DA \& Miron JA (1994). Global pattems of seasonal variation in human fertility. Annals of the New York Academy of Sciences, 709: 9-28.
3. Anonymous (1985). Geigy Scientific Tables. Statistics. 8. Auflage. Ciba Geigy, Basel, Switzerland.

4. Sachs L (1984). Angewandte Statistik. Anwendung Statistischer Methoden. 6. Auflage. Springer-Verlag, Berlin, Heidelberg, New York, Tokyo.

5. Weber E (1967). Grundriss der Biologi- schen Statistik. Anwendungen der Mathematischen Statistik in Naturwissenschaft und Technik. 6. Auflage. VEB Gustav Fischer Verlag, J ena, Germany.

6. Fisher RA (1929). Tests of significance in harmonic analysis. Proceedings of the Royal Society of London. Series B: Biological Sciences, 125: 54-59. 
7. Ondrejka P \& Kubacek L (2000). PeriProb. Computer program for periodogram analysis. ComTel, Bratislava, Slovakia.

8. Bingham Ch, Arbogast B, Comelissen GG, Lee JK \& Halberg $F$ (1982). Inferential statistical methods for estimating and comparing cosinor parameters. Chronobiologia, 9: 397-439.

9. Kubacek L \& Valach A (2000). Time series analysis including periodic components. Computer program. ComTel, Bratislava, Slovakia.

10. Holland BS, DiPonzio Copenhaver M (1987). An improved sequentially rejective Bonferroni test procedure. Biometrics, 43: 417-423.

11. Guillon P, Guillon D, Lansac J, Soutoul J H, Bertrand P \& Hornecker J P (1986). Births, fertility, rhythms and lunar cycle. A statistical study of 5,927,978 births. J ournal de Gynecologie, Obstetrique et Biologie de la Reproduction, 15: 265-271.

12. Guillon $P$, Guillon $D$, Pierre $F \&$ Soutoul J H (1988). Seasonal, weekly and lunar cycles of birth. Statistical study of $12,035,680$ births. Revue Francaise de Gynecologie et d'Obstetrique, 83: 703-708.

13. Ghiandoni $\mathrm{G}$, Secli R, Rocchi MB \& Ugolini $G$ (1997). Incidence of lunar position in the distribution of deliveries. A statistical analysis. Minerva Ginecologica, 49: 9194.

14. Ghiandoni $G$, Secli R, Rocchi MB \& Ugolini $G$ (1998). Does lunar position influence the time of delivery? A statistical analysis. European J ournal of Obstetrics, Gynecology, and Reproductive Biology, 77: 47-50.

15. Ghiandoni G, Secli R, Rocchi MB, Ugolini $G \&$ Cancelli V (1998). Some unexpected results in time distribution analysis of spontaneous deliveries. Gynecologic and Obstetric Investigation, 46: 88-90.

16. Stern Ellen W, Glazer GL \& Sanduleak N
(1988). Influence of the full and new moon on onset of labor and spontaneous rupture of membranes. J ournal of Nurse-Midwifery and Women's Health, 33: 57-60.

17. Trap R, Helm P, Lidegaard $O$ \& Helm E (1989). Premature rupture of the fetal membranes, the phases of the moon and barometer readings. Gynecologic and $\mathrm{Ob}-$ stetric Investigation, 28: 14-18.

18. Arrhenius S (1898). Die Einwirkung kosmischer Einflüsse auf physiologische Verhältnisse. Scandinavian Archives of Physiology, 8: 367-415.

19. Mikulecky M (1993). Arrhenius moon paper: forgotten? In: Mikulecky M (Editor), Moon and Living Matter. Proceedings of International Workshop. Slovak Medical Society, Kosice, Slovakia, 10-13.

20. Hausser Ch, Bomais R \& Bomais S (1985). L'influence du cycle lunaire sur les accouchements. Union Medicale du Canada, 114: 548-550.

21. Martens R, Kelly IW \& Saklofske DH (1988). Lunar phase and birth-rate: a 50year critical review. Psychological Reports, 63: 923-934.

22. Strolego F, Gigli C \& Bugalho A (1991). Influenza delle fasi lunari sulla frequenza dei parti. Minerva Ginecologica, 43: 359363.

23. Kelly IW \& Martens R (1994). Geophysical variables and behavior: LXXVIII. Lunar phase and birthrate: an update. Psychological Reports, 75: 507-511.

24. Periti E \& Biagiotti $R$ (1994). Fasi lunari ed incidenza di parti spontanei. Minerva Ginecologica, 46: 429-433.

25. Wunder E (1995). Geburtshelfer Mond? Zum paranormalen Überzeugungssystem des Lunatismus und seiner empirischen Überprüfung. Teil 1: Die Forschungsgeschichte von 1829 bis heute. Skeptiker, 1: 7-14.
26. Wunder E (1995). Geburtshelfer Mond? Zum paranormalen Überzeugungssystem des Lunatismus und seiner empinischen Überprüfung. Teil 2: Weitere schlechte Nachrichten für Mondgläubige. Skeptiker, 2: 51-57.

27. Verhulst J (2000). Moon phase at the date of birth and decease of anthroposophic pioneers. Medical Hypotheses, 54: 648651.

28. Verhulst J (2000). World cup soccer players tend to be born with sun and moon in adjacent zodiacal signs. British J ournal of Sports Medicine, 34: 465-466.

29. Mikulecky M \& Valachova A (1996). Lunar influence on atrial fibrillation? Brazilian J ournal of Medical and Biological Research, 29: 1073-1075.

30. Mikulecky J r M \& Ondrejka P (1993). Moon cycle and acute diarmeal infections in Bratislava 1988-1990. In: Gutenbrunner Ch, Hildebrandt G \& Moog R (Editors), Chronobiology and Chronomedicine. P. Lang, Frankfurt a.M., Berlin, Bem, New York, Paris, Wien, 356-360.

31. Derer L (1960). Rhythm and proliferation with special reference to the six day rhythm of blood leukocyte count. Neoplasma, 7: 117-134.

32. Halberg $F$ (1993). More on chronome: circaseptans and circasemiseptans in Marburg, Germany, and 47 other locations. Chronobiologia, 20: 119-122.

33. Halberg F \& Comelissen G (1993). Genetically anchored multiseptans, multiples of 3.5-day rhythms responsive to drummers distant in time-space? In: Mikulecky M (Editor), Moon and Living Matter. Proceedings of Intemational Workshop. Slovak Medical Society, Kosice, Slovakia, 8190. 